\title{
correspondence
}

\section{Laboratory charges}

SIR,-I am much in sympathy with Kenneth Mellanby (October 2) and especially his final paragraph on inexpensive biological research. Having simple research needs-eyes, a waterproof and time for fieldwork and contemplation-I have been conscious throughout my career as a littoral ecologist, of the patronising designation 'only a naturalist' from those who think that little of value can be achieved without, for example, an autoanalyser, an atomic absorption spectrophotometer or an electron microscope. Tempted though I have been at times to try to impress visitors with a benchful of borrowed equipment and some coloured liquids their attitude has nevertheless remained as water on a limpet's back, and the major events of recent years have finally reinforced my conviction that a field of biology that is important but relatively inexpensive, that appears simple but is very challenging, has been ignored in favour of the esoteric and the elaborate.

This event is the 'ecological crisis', and more particularly within my own discipline the dawning realisation that by generally eschewing organismal biology for several decades marine biologists are not now able to tell society with conviction the state of affairs in the sea or along the coast. Time after time one is asked if pollution is affecting local populations, if a scarcity of this or an abundance of that is natural or not. With embarrassment one admits to ignorance, except in obviously severe instances, and then, in response to mutterings about taxpayers' money and what biologists have been doing all these years, one loyally defends colleagues who did not find it worthwhile intellectually or in career terms to count organisms, or to study their biological interactions, their reproductive cycles, their behaviour or even how long they live-all of which would have hetter enabled us to assess the present field situation and respond to the public concern. But attitudes are changing; the doom-mongers have, after all, done biology a service.

To those who may wonder what to turn to if their capital investment should be rendered valueless by an inability to meet the unforeseen but swingeing maintenance contracts, may I offer a suggestion? Lend a hand on a field course and encourage accurate observation and speculation about what organisms do, how they live in a complex natural situation. The range of as yet unanswerable questions about even the most common species that will surely arise from a class of enquiring minds will not only be humbling but will point to many rewarding research projects. In short, natural history appears in many up-dated guises but still presents unlimited and relevant challenges.

Yours faithfully, J. R. LEwIS

Wellcome Marine Laboratory, University of Leeds, UK

\section{This week's free offer}

SIR, - In a recent BBC "Controversy" programme, Professor John Taylor expressed strongly his opinion that scientists were stifling science. One of his points of contention was that he had been unable to obtain a grant from the Science Research Council to support investigations into the supposed paranormal phenomena associated with Uri Geller and others, including some children. In discussion he said that he had not the facilities for a thoroughgoing scientifically controlled experiment and mentioned that these could include such expensive items as electron microscopes and audiovisual recording equipment.

The phenomenon most frequently mentioned is the deformation and fracture of metallic objects without the application of the relatively large stresses normally to be associated with such changes in the metal shape. If it were true and could be substantiated, this would be an entirely new metallurgical phenomenon.

The equipment required for its investigation, including all the items mentioned by Professor Taylor, is available in this department and could be used for a definitive experiment. I would therefore like to invite Professor Taylor to join with us in devising a controlled experiment which would test the authenticity of the claims made by those, and particularly Uri Geller, who say that they can bend metallic objects without the direct application of the stresses normally required.

I would suggest that to establish the experiment's authenticity, its control and observation by independent witnesses should be approved beforehand by yourself and/or a nominated panel of scientists and conjurors. The experiment could be devised to be definitive and its cost would be very small in relation to the importance of the claims that have been made. Professor Taylor need have no recourse to financial resources as the conduct of the experiment would be within the normal research activities of a department such as this. I very much hope that Professor Taylor will be willing to take up this proposal.

Yours faithfully, J. G. BALL

Department of Metallurgy and

Materials Science,

Imperial College, London, UK

\section{Cheating children}

SIR,-Professor Taylor has cited a remark of Sir William Crookes on the relative susceptibility to deception of physicists and conjurers. It would materially help in weighing this statement if he would tell us whether it was uttered before or after Sir William had disgraced the scientific calling by becoming an accomplice of the fake medium Eliza Cook; if the latter, was it before or after the conjurer Maskelyne indicated the mechanism of deceit?

Yours faithfully, M. Hammerton University of Newcastle upon Tyne, UK

\section{Out of town}

SIR,-May a humble linguist point out that "commanded out" ("Publishing problems", September 4) is probably an attempted translation of the German abkommandiert, which is a military (and probably bureaucratic) term meaning "temporarily transferred" to another place ("detached" is the English term as opposed to a permanent "posting"). Central Europeans, particularly scientists and technologists, often use German as a lingua franca; and central Europeans tend to be rather 'disciplined' in their jargon as opposed to the trendy Anglo-American 'free-and-easy' style. It is all a matter of custom. Without prejudice to your correspondent's point, his friend may merely have meant to say "I was out of town for a couple of weeks, and couldn't reply earlier".

Yours faithfully,

A. I ODGE

Swanley, Kent, UK 